\title{
Cause of Delay in Treatment in Cases of Abdominal Malignancies
}

\author{
Rashmi S. ${ }^{1}$, Suhas N. Jajoo², Darshana Tote ${ }^{3}$, Meenakshi Yeola ${ }^{4}$ \\ 1, 2, 3,4 Department of General Surgery, Datta Meghe Institute of Medical Sciences (Deemed to Be University), \\ Sawangi (Meghe), Wardha, Maharashtra, India.
}

\section{ABSTRACT}

\section{BACKGROUND}

Abdominal malignancies are a common problem in the western countries and is on a rise in India. This study was conducted to evaluate the reasons for delay in diagnosis and treatment of cancer.

\section{METHODS}

This is a prospective observational study conducted in the Department of Surgery Acharya Vinobha Bhave Rural Hospital, Sawangi (Meghe), Wardha, for a period of 2 years with a sample size of 46 patients.

\section{RESULTS}

Delay in presentation was noted in $74 \%$ of patients. Among them 'taking local treatment' was considered to be the main cause of delay in treatment. There was delay in diagnosis in $8 \%$ of patients. There was delay in initiation of treatment in 18 $\%$ of patients.

\section{CONCLUSIONS}

Most of the patients presented in advanced stages to the hospital because of taking local treatment, due to lack of awareness, belief in herbal and ayurvedic treatment, poor financial resources, and fear of surgery. The proper treatment was delayed or denied leading to poor overall outcome.

\section{KEY WORDS}

Delay, Presentation, Diagnosis, Treatment
Corresponding Author:

Dr. Rashmi $S$,

Flat no. C1, Honey Heights Apartments, Near SBI Bank,

Sawangi (Meghe),

Wardha-442001,

Maharashtra, India.

E-mail: rashmis2993@gmail.com

DOI: $10.14260 /$ jemds/2021/205

How to Cite This Article:

Rashmi S, Jajoo SN, Tote D, et al. Cause of delay in treatment in cases of abdominal malignancies. J Evolution Med Dent Sci 2021;10(13):952-955, DOI: 10.14260/jemds/2021/205

Submission 18-11-2020,

Peer Review 30-01-2021,

Acceptance 06-02-2021,

Published 29-03-2021.

Copyright (C) 2021 Rashmi S. et al. This is an open access article distributed under Creative Commons Attribution License [Attribution 4.0 International (CC BY 4.0)] 


\section{BACKGROUND}

Abdominal malignancies are a common problem in the western countries and is on a rise in India due to changes in lifestyle. Lifestyle factors include smoking, obesity, increased consumption of red meat, processed foods and increased incidence of diabetes mellitus. ${ }^{1}$ Colorectal cancer is the $3^{\text {rd }}$ most common in males and $2^{\text {nd }}$ most common in females. Gastric cancer is the $4^{\text {th }}$ and $7^{\text {th }}$ most common in males and females, respectively. Liver cancer is the 5 th and 9th most common cancer in males and females, respectively. Gall bladder, pancreas and small intestine cancers are less common. In men liver, stomach, colorectal and pancreas are the $2^{\text {nd }}, 3^{\text {rd }}, 4^{\text {th }}$ and $7^{\text {th }}$ leading causes of mortality whereas in the female it is $6^{\text {th }}, 4^{\text {th }}, 3^{\text {rd }}$ and $7^{\text {th }}$ respectively. ${ }^{2}$

Several reasons for delays are seen in initiation of cancer treatment. Primary delay is the duration from beginning of symptoms to presenting to the doctor and secondary delay is from presenting to the doctor to initiation of treatment. ${ }^{1}$ Primary delay (PD) is also called patient delay because these reasons are from the patient such as lack of awareness, low socio-economic status, financial problems etc. Secondary or doctor delay (SD) includes the patient's characteristics as well as doctor and system related reasons. ${ }^{1}$ The practice of patients seeing one general physician (GP) throughout their lifetime is reducing, and patients report less continuity of care and more difficulty in seeing a consistent doctor. ${ }^{3}$

Within the patient interval there are two component intervals; symptom appraisal (the period between detecting a bodily change and deciding that there is a need to discuss the symptoms with a health care practitioner) and help-seeking (the period from perceiving a need to discuss the symptoms with a health care practitioner to the first consultation). Symptom misinterpretation is frequently reported, with patients believing their symptoms are the result of minor ailments, physical exertion, stress, connected to pre-existing conditions, ageing or expected bodily changes.

Fear plays an important yet unclear role in help-seeking. Fear can manifest itself as a fear of cancer or of the investigations and treatments associated with it. Fear of embarrassment and shame can also act as a barrier to presentation, particularly when symptoms are located in 'private' areas of the body. Some patients only report their symptoms during consultations for other conditions or monitor their symptoms in order to accumulate 'evidence' to justify presentation. Social context has been shown to influence the timing of help-seeking, particularly the prioritisation of other life events. Social networks are also thought to be influential, through the sanctioning of helpseeking, and / or identification of symptoms. ${ }^{4}$

In the hospital, delays may be from doctors' side in reaching a diagnosis and initiation of treatment. A doctors' delay in reaching to a diagnosis is duration from primary care referral to diagnosis. Diagnostic delay may occur if many invasive investigations are required to reach or for confirmation of the diagnosis and to determine the operability and appropriate surgical treatment. ${ }^{2}$ Delays in primary care can be related to diagnostic error, with cancer the most widely identified condition associated with diagnostic error in primary care. Features associated with diagnostic error include atypical presentations, non-specific presentations, very low prevalence of the disease in the general population and comorbidities. ${ }^{5}$ Apart from the various prognostic factors individually discussed for cancers, delay in the diagnosis and treatment forms an important factor for adverse outcomes. ${ }^{2}$ Abdominal malignancies due to their non-specific signs and symptoms may also have a delayed diagnosis and presentation which can lead to delay in the diagnosis and management. ${ }^{3}$

This study was conducted to evaluate the various causes of delay in diagnosis and treatment of malignancies.

\section{METHODS}

The current study was conducted in the Department of Surgery at a rural tertiary health care centre - Acharya Vinobha Bhave Rural Hospital, Sawangi (Meghe), Wardha. It is a prospective observational study conducted over a period of 2 years (from September 2018 to August 2020). All patients attending Department of Surgery OPD and admitted to AVBRH hospital for the treatment of abdominal malignancies were included in the study. Patients with gynaecological cancers, urological cancers and malignancies of sites other than abdomen were excluded from the study. 46 patients were included in this study.

\section{Data Collection}

Patients eligible for the study were identified based on the inclusion and exclusion criteria. A detailed history was taken from each of the patients regarding the appearance of symptoms and the reason for delay in presentation to the hospital. They were observed throughout their hospital stay. The reason for delay in diagnosis and initiation of treatment were noted.

\section{Data Compilation and Presentation}

The collected data was compiled. A master table was prepared, and the data set was subdivided and distributed and presented as individual tables along with graphs on a Microsoft Excel Worksheet (Microsoft, USA).

\section{RESULTS}

In the present study, out of 46 patients, 34 patients presented late to hospital, 14 ( $41 \%$ ) patients ( 2 stomach, 1 pancreas, 4 proximal colon, 2 distal colon and 5 rectum \& anal canal) due to taking local symptomatic treatment without definitive diagnosis, 6 (17\%) patients ( 1 stomach, 1 gall bladder, 1 distal colon and 3 rectum \& anal canal) due to lack of awareness, 5 (15\%) patients ( 2 pancreas, 1 distal colon and 2 rectum \& anal canal) due to taking herbal treatment, 4 (12\%) patients (2 proximal colon, 1 distal colon and 1 rectum \& anal canal) due to financial reasons, $3(9 \%)$ patients (1 proximal colon and 2 rectum \& anal canal) due to ayurvedic treatment without definitive diagnosis and $2(6 \%)$ patients $(1$ stomach and 1 rectum \& anal canal) due to not willing for surgery.

In the present study, out of 46 patients, in 4 patients there was delay in diagnosis, in $2(50 \%)$ patients $(1$ pancreas and 1 proximal colon) delay was due to poor compliance of the patients, in $1(25 \%)$ patient (1 distal colon) delay was due to 
non-availability of particular doctor, in 1 (25\%) patient (1 distal colon) delay was due to repeated biopsies needed for confirmation.

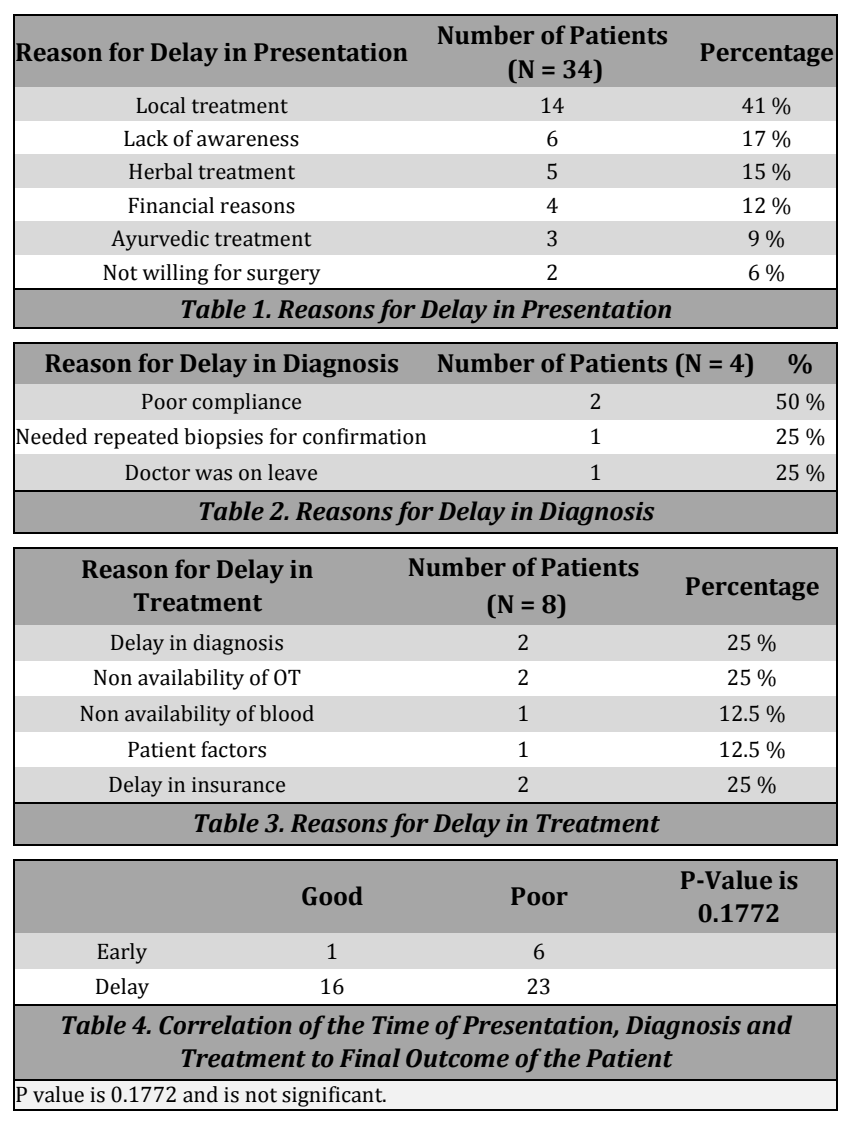

In the present study, treatment was delayed in 8 patients, in $2(25 \%)$ patients ( 2 distal colon) due to delay in diagnosis due to poor patient compliance, in 2 (25\%) patients (1 stomach and 1 distal colon) delay was due to non-availability of operation theatre (OT) due to many holidays, in 1 (14\%) patient due to non-availability of B negative blood, in 1 (14\%) patient (1 proximal colon) due to patient delaying treatment due to family programme and in $2(29 \%)$ patients (1 proximal colon and 1 distal colon) due to delay in insurance.

In the present study, out of 46 patients, 7 patients presented early, 1 had good outcome and 6 patients had poor outcome. 39 patients either presented late to hospital, or the diagnosis was delayed, or the treatment was delayed; 16 patients had good outcome and 23 patients had poor outcome.

\section{DISCUSSION}

Vivek Tiwari et al. in their study concluded that the patient's factors are the major causes of delay as compared to hospital factors. Reasons for this delay comprised of unawareness regarding the signs and symptoms of cancer, consultation with unqualified local practitioners / no consultation, use of alternative medication, poor socio-economic conditions and lack of a proper referral infrastructure. ${ }^{6}$

A K Dwivedi et al. in their study observed the causes for delay in presentation in $54.6 \%$ patients due to lack of awareness, $12.4 \%$ patients due to economic problems, $3.5 \%$ patients due to fear of cancer, $4.5 \%$ patients distance problems, $8.7 \%$ due to family problems, $30 \%$ of the patients made more than two medical contacts for confirming the diagnosis. ${ }^{7}$ Hospital factors as cause of delay include in $27.5 \%$ patients inappropriate diagnosis, $50 \%$ patients were advised symptomatic treatment before establishment of diagnosis, $7 \%$ of the patients were assured that the disease is not a matter of serious concern and $60 \%$ of the patients contacted small clinics / primary health centres. ${ }^{7}$

Mohammed $\mathrm{H}$ al azri et al. in their study observed that a delay in cancer diagnosis can occur at various levels. The patient may fail to recognise suspicious cancer symptoms or act on them. The primary care physician may not recognise patients with suspicious cancer symptoms and may not advise for proper investigation or may not refer the cancer patients on time. Patients with suspicious cancer in secondary care may not be seen on time, or they may be referred to the wrong specialty. ${ }^{5}$ My study is correlating with Vivek Tiwari et al., A K Dwivedi et al. and Mohammed $\mathrm{H}$ al azri et al.

Most of the patients presented in advanced stages to the hospital because of taking local treatment ( $41 \%$ ) or moving from one doctor to other. This is because there is lack of awareness (17\%), belief in herbal (15\%) and ayurvedic (9\%) treatment, poor financial resources (12\%), and fear for surgery (6\%). The proper treatment is delayed or denied leading to poor overall outcome.

Delay in diagnosis is again mainly due to poor compliance of patient being irregular for investigations due to personal reasons $(50 \%)$. The other reasons are non-availability of particular doctor (25\%), repeated negative biopsy reports (25 $\%)$. Delay in treatment is mainly due to delay in diagnosis (25 $\%)$ as biopsies were either inadequate tissue or reported as definite opinion could not be given, non-availability of OT (25 $\%)$ or delay in MJPJAY (25 \%).

\section{CONCLUSIONS}

There are many social, familial and personal factors in delay and that can only be tackled if social workers remain in contact with these patients and promote and counsel them to take advised treatment. A health education and screening program should be implemented in the rural areas. This will help in reducing the delay in presentation to the hospital. Patients should be guided regarding the necessity of treatment. Patients should be provided facility of insurance schemes and free health care facilities so that the patients do not refuse treatment. Transportation facilities between the health care centre and rural areas improve the communication and prevents delayed presentation. Prevention of delay in presentation, proper screening tests, and counselling of highrisk groups will reduce delay. It will also help in early detection of these malignancies.

Old age of patient, lack of family support, poor financial condition, obtaining local treatment / ayurvedic treatment, symptoms being neglected by people or misinterpreted by local doctor, lack of medical help, non-availability of investigation tools, poor government facilities, heavy patient load and fear within the patient to go to the hospital are important factors. 


\begin{tabular}{|c|c|c|c|c|c|c|c|c|}
\hline $\begin{array}{l}\text { Sl. } \\
\text { No. }\end{array}$ & Patient ID & Age & Sex & $\begin{array}{l}\text { Early / } \\
\text { Delayed }\end{array}$ & $\begin{array}{l}\text { Patient Factors / } \\
\text { Hospital Factors }\end{array}$ & & Surgery Done / Not & Outcome \\
\hline 1 & 1812080021 & 50 & Male & Delayed & Patient factors & Herbal treatment & Anterior Resection & Good \\
\hline 2 & 1806150032 & 35 & Male & Delayed & Patient factors \& hospital factors & $\begin{array}{l}\text { Local treatment \& delayed insurance } \\
\text { scheme approval }\end{array}$ & Right hemicolectomy & Good \\
\hline 3 & 1806260119 & 35 & Male & Delayed & Patient factors & Ayurvedic treatment & Abdominoperineal resection & Good \\
\hline 4 & 1904160009 & 56 & Female & Delayed & Hospital factors & Non availability of OT & Abdominoperineal resection & Poor \\
\hline 5 & 1907220207 & 45 & Male & Delayed & Hospital factors & Doctor was unavailable & Left hemicolectomy & Good \\
\hline 6 & 1810020012 & 40 & Female & Delayed & Hospital factors & Multiple biopsies & Palliative & Death \\
\hline 7 & 1811080015 & 50 & Female & Delayed & Patient factors & Local treatment & Right hemicolectomy & Good \\
\hline 8 & 1902050053 & 57 & Male & Delayed & Patient factors \& hospital factors & $\begin{array}{c}\text { Irregular for investigations \& delay in } \\
\text { diagnosis }\end{array}$ & Palliative & Death \\
\hline 9 & 1903180108 & 62 & Female & Delayed & Patient factors & Local treatment & Palliative & Death \\
\hline 10 & 1906180169 & 66 & Male & Delayed & Hospital factors & Non availability of blood & Anterior resection & Good \\
\hline 11 & 1807280025 & 55 & Male & Delayed & Patient factors & Not willing for surgery & Palliative & Death \\
\hline 12 & 1910300135 & 45 & Female & Delayed & Patient factors & Herbal treatment & Palliative & Death \\
\hline 13 & 1905160113 & 70 & Male & Early & - & - & Palliative & Death \\
\hline 14 & 1902220108 & 44 & Female & Early & - & - & Resection and anastomosis & Death \\
\hline 15 & 1905230064 & 50 & Female & Delayed & Patient factors & Lack of awareness & Anterior resection & Good \\
\hline 16 & 1903080037 & 58 & Male & Delayed & Patient factors \& hospital factors & Lack of awareness & Abdominoperineal resection & Death \\
\hline 17 & 1902230042 & 44 & Female & Early & 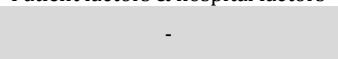 & 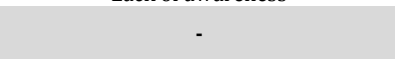 & $\begin{array}{l}\text { Laparoscopic } \\
\text { cholecystectomy }\end{array}$ & Good \\
\hline 18 & 1807170066 & 45 & Female & Delayed & Patient factors & Financial reasons & Palliative & Death \\
\hline 19 & 1910310093 & 58 & Male & Delayed & Patient factors & Local treatment & Palliative & Death \\
\hline 20 & 1810120048 & 55 & Female & Delayed & Patient factors & $\begin{array}{c}\text { Lack of awareness \& non availability of } \\
\text { OT }\end{array}$ & Gastrectomy & Death \\
\hline 21 & 1908260091 & 60 & Female & Delayed & Patient factors & Financial reasons & Left hemicolectomy & Good \\
\hline 22 & 1907240068 & 65 & Male & Delayed & Patient factors & Local treatment & Anterior resection & Good \\
\hline 23 & 1909230109 & 42 & Female & Delayed & Hospital factors & Local treatment & Resection and anastomosis & Good \\
\hline 24 & 1808280158 & 72 & Female & Delayed & Patient factors & Lack of awareness & Palliative & Death \\
\hline 25 & 1812230021 & 58 & Male & Delayed & Patient factors & Local treatment & Palliative & Death \\
\hline 26 & 1901170051 & 59 & Male & Delayed & Patient factors & Herbal treatment & Palliative & Death \\
\hline 27 & 1904180046 & 62 & Female & Delayed & Patient factors \& hospital factors & Ayurvedic treatment & Abdominoperineal resection & Good \\
\hline 28 & 1908140062 & 55 & Male & Early & - & - & Palliative & Death \\
\hline 29 & 1808230016 & 44 & Male & Delayed & Patient factors \& hospital factors & Local treatment & Palliative & Death \\
\hline 30 & 1904160106 & 73 & Female & Early & - & - & Right hemicolectomy & Death \\
\hline 31 & 1901240028 & 40 & Female & Delayed & Patient factors \& hospital factors & $\begin{array}{l}\text { Lack of awareness \& delayed insurance } \\
\text { scheme approval }\end{array}$ & Abdominoperineal resection & Death \\
\hline 32 & 1809290089 & 87 & Female & Delayed & Patient factors \& hospital factors & Local treatment & Abdominoperineal resection & Death \\
\hline 33 & 1810030021 & 40 & Female & Delayed & Patient factors \& hospital factors & Lack of awareness & Anterior resection & Good \\
\hline 34 & 1902150035 & 48 & Female & Delayed & Patient factors \& hospital factors & Local treatment & Abdominoperineal resection & Good \\
\hline 35 & 1904170030 & 55 & Female & Delayed & Patient factors & Herbal treatment & $\begin{array}{l}\text { Palliative } \\
\text { P }\end{array}$ & Death \\
\hline 36 & 1905140048 & 49 & Male & Delayed & Patient factors \& hospital factors & Not willing for surgery & Gastrectomy & Good \\
\hline 37 & 1903220023 & 55 & Male & Delayed & Patient factors \& hospital factors & Ayurvedic treatment & Right hemicolectomy & Death \\
\hline 38 & 1907080120 & 46 & Male & Delayed & Patient factors & Financial reasons & Palliative & Death \\
\hline 39 & 1907080031 & 57 & Male & Delayed & Patient factors & Local treatment & Palliative & Death \\
\hline 40 & 1811220040 & 65 & Male & Delayed & Patient factors & Herbal treatment & Abdominoperineal resection & Good \\
\hline 41 & 1806050107 & 60 & Male & Delayed & Patient factors & Local treatment & $\begin{array}{l}\text { Palliative } \\
\text { Pat }\end{array}$ & Death \\
\hline 42 & 1903060085 & 60 & Female & Delayed & Patient factors \& hospital factors & Financial reasons & Right hemicolectomy & Good \\
\hline 43 & 1811230007 & 58 & Male & Delayed & Patient factors & $\begin{array}{l}\text { Local treatment \& irregular for } \\
\text { investigations }\end{array}$ & Right hemicolectomy & Poor \\
\hline 44 & 1807110030 & 68 & Male & Delayed & Patient factors & Local treatment & Palliative & Death \\
\hline 45 & 1810260128 & 65 & Male & Early & - & - & Palliative & Death \\
\hline 46 & 1909180078 & 50 & Female & Early & - & - & Palliative & Death \\
\hline \multicolumn{9}{|c|}{ Table 5. Master Chart on Delay } \\
\hline
\end{tabular}

Cost involved add to the agony. Slow moving hospital evaluation, incompleteness of investigations, non-availability of blood, drugs and specific treating doctor, and nonavailability of OT time are resource related causes. Social backup and security, streamlining hospital functioning, availability of infra-structure and facilities, utilisation of social workers are very important. The following steps should be taken-

1. Village level - Training of social worker \& peripheral health worker.

2. Doctor's training - Medical education program.

3. Hospital structure - Screening, identification targeted clinics with medical team support and staff.

4. Comfort, assurance, counselling to patient.

5. Early disposal - Diagnosis and treatment at subsidised cost / insurance.

6. Post-operative follow up and care - Social worker and peripheral health worker.

Data sharing statement provided by the authors is available with the full text of this article at jemds.com.

Financial or other competing interests: None.

Disclosure forms provided by the authors are available with the full text of this article at jemds.com.

\section{REFERENCES}

[1] Dwivedi AK, Dwivedi SN, Deo S, et al. An epidemiological study on delay in treatment initiation of cancer patients. Health 2012;4(2):66-79.

[2] Bray F, Ferlay J, Soerjomataram I, et al. Global cancer statistics 2018: GLOBOCAN estimates of incidence and mortality worldwide for 36 cancers in 185 countries. CA Cancer J Clin 2018;68(6):394-424.

[3] Round T, Steed L, Shankleman J, et al. Primary care delays in diagnosing cancer: what is causing them and what can we do about them? J R Soc Med 2013;106(11):437-40.

[4] Dobson CM, Russell AJ, Rubin GP. Patient delay in cancer diagnosis: what do we really mean and can we be more specific? BMC Health Serv Res 2014;14:387.

[5] Al-Azri MH. Delay in cancer diagnosis: causes and possible solutions. Oman Med J 2016;31(5):325-6.

[6] Tiwari V, Yogi V, Ghori HU, et al. Identifying the factors causing delayed presentation of cancer patients to a Government Medical College of central India. J Clin Diagn Res 2015;9(9):XC09-XC12.

[7] Mohandas KM. Colorectal cancer in India: controversies, enigmas and primary prevention. Indian J Gastroenterol 2011;30(1):3-6. 